\title{
PENGARUH PEMBERIAN PERSEPULUHAN \\ ATAS KEROHANIAN GEREJA SIDANG JEMAAT ALLAH \\ JEMAAT VICTORIOUS WORSHIP FAMILY MAKASSAR
}

\author{
Christina Evi Paligi \\ Ivan Th. J. Weismann \\ Sekolah Tinggi Filsafat Theologia Jaffray \\ ivanweismnn@yahoo.com
}

\begin{abstract}
ABSTRAK
Yang menjadi pokok masalah dalam penulisan karya ilmiah ini adalah sejauh mana sikap jemaat dalam hal perpuluhan berpengaruh atas perkembangan rohani, dan sejauh mana sikap jemaat dalam perpuluhan berpengaruh atas perkembangan usaha. Tujuan penulisan ini ialah untuk mencari tahu faktorfaktor apa yang menyebabkan jemaat tidak setia dalam memberi persepuluhan kepada Tuhan, dan untuk mencari tahu mengapa jemaat tidak memahami dengan benar tentang persepuluhan. Penelitian akan mengambil sample yang terdiri dari 50 anggota jemaat yang sudah berpenghasilan. Teknik pengumpulan data melalui angket dan teknik analisis data yaitu penggunaan analisis statistic dengan program SPSS 15. Adapu hasiul penelitian bahwa tingkat pendidikan jemaat GSJA Victorious Worship Family Makassar sangat berpengaruh terhadap perkembangan rohani jemaat, di mana apabila terjadi peningkatan pada tingkat pendidikan jemaat maka perkembangan rohaninya mengalami penurunan. Kedua, bahwa tingkat pendidikan jemaat sangat berpengaruh terhadap keberhasilan usaha jemaat, di mana apabila terjadi peningkatan pada tingkat pendidikan jemaat maka keberhasilan usaha jemaat mengalami peningkatan. Ketiga, bahwa tingkat pendidikan jemaat sangat berpengaruh terhadap sikap memberi persepuluhan kepada Tuhan, di mana apabila terjadi peningkatan pada tingkat pendidikan maka tingkat sikap memberi persepuluhan kepada Tuhan mengalami perkembangan.
\end{abstract}

Kata kunci: Persepuluhan, perkembangan rohani, keberhasilan usaha

\section{PENDAHULUAN}

\section{Latar Belakang Masalah}

Persepuluhan bukanlah suatu kata yang baru bagi kalangan gereja masa kini, melainkan telah diajarkan turun temurun, baik di dalam gereja maupun di dalam rumah tangga itu sendiri. Persepuluhan adalah merupakan suatu perintah Allah dan kewajiban bagi setiap orang percaya untuk mengembalikan apa yang menjadi milik Tuhan dari sepuluh persen dari hasil setiap orang percaya, baik itu berupa uang, tanah, ternak dan lainlain. Kejadian 28 : 20 - 22 "Dari segala sesuatu yang Engkau berikan kepadaku akan selalu kupersembahkan sepersepuluh kepada-Mu." Imamat 27 : 30 - 34, "Demikian juga segala persembahan persepuluhan dari tanah, baik dari hasil benih dari tanah maupun dari buah pohon-pohonan milik Tuhan: itulah persembahan kudus bagi Tuhan." Maleakhi 3:6-10, "Bawalah persembahan persepuluhan itu ke dalam rumah perbendaharaan, supaya ada persediaan makanan di Rumah-Ku dan ujilah Aku ...." Matius 22 : 15 - 22, "Berikanlah kepada Kaisar apa yang wajib kamu berikan kepada Kaisar, kepada Allah apa yang wajib kamu berikan kepada Allah."

Persepuluhan adalah prinsip yang sangat penting diajarkan dan dilakukan oleh setiap orang percaya seperti yang dikatakan oleh Robert Cowles, "Memang harus diakui bahwa 
persepuluhan itu merupakan prinsip yang terdapat dalam Perjanjian Lama tetapi di dalam Perjanjian Baru hal itu dibenarkan oleh Tuhan Yesus." Lebih lanjut Robert Cowles mengatakan, "Gereja-gereja Kristen yang benar-benar sudah menyerahkan diri, sedikitnya akan memberikan persepuluhan ditambah dengan persembahan-persembahan lain sebagaimana Allah memberkatinya." ${ }^{2}$

Persepuluhan menjadi bagian hidup setiap orang percaya, karena Allah adalah pencipta segala sesuatu, itu berarti orang yang percaya selalu diberkati Allah. Dengan demikian tidak ada alasan bagi orang percaya untuk tidak memberi persepuluhan kepada Allah seperti yang dikatakan oleh Jeff Hammond,

Membayar perpuluhan adalah suatu kebenaran yang penting sekali, dan perlu dilaksanakan oleh setiap anggota jemaat. Dengan menaati kebenaran ini maka kita akan berkembang secara rohani sedangkan kalau kita menolak kebenaran ini, hal itu akan menghambat perkembangan rohani kita, bahkan menunjukkan keadaan suam rohani kita. ${ }^{3}$

Dikatakan bahwa perpuluhan itu penting untuk perkembangan rohani dan untuk diberkati. Orang Kristen yang memberi perpuluhan adalah orang Kristen yang telah menyerahkan diri. Menyerahkan diri seperti menjadi anggota gereja, aktif di dalam gereja dan memberi perpuluhan, tetapi secara rohani dan ekonomi tidak berkembang, ekonominya relatif tidak ada perkembangan berarti.

Seyogyanya dikatakan bahwa indikator kerohanian adalah komitmen pada perpuluhan. Tetapi kenyataannya anggota jemaat GSJA Victorious Worship Family Makassar sudah setia dalam melayani dan juga sudah setia dalam memberikan perpuluhan kepada Tuhan tetapi secara rohani dan ekonomi tidak mengalami perkembangan seperti yang diinginkan.

Sehubungan yang ada di GSJA Victorious Worship Family Makassar bahwa sesungguhnya sikap jemaat dalam memberi persepuluhannya kepada Allah berpengaruh atas perkembangan rohani dan perkembangan usaha jemaat.

Melalui fakta di atas membuat penulis tertarik untuk mengembangkan tulisan ini dalam suatu karangan ilmiah yang berjudul: "PENGARUH PEMBERIAN PERSEPULUHAN ATAS PERKEMBANGAN ROHANI GEREJA SIDANG JEMAAT ALLAH JEMAAT VICTORIOUS WORSHIP FAMILY MAKSSAR.”

\section{Pokok Masalah}

Yang menjadi pokok masalah bagi penulis dalam penulisan karya ilmiah ini adalah: Pertama, Sejauh mana sikap jemaat dalam hal perpuluhan berpengaruh atas perkembangan rohani. Kedua, Sejauh mana sikap jemaat dalam perpuluhan berpengaruh atas perkembangan usaha.

\section{Tujuan Penulisan}

Dalam penulisan karya ilmiah ini ada beberapa tujuan yang diharapkan untuk dicapai, yaitu: Pertama, Untuk mencari tahu faktor-faktor apa yang menyebabkan jemaat tidak setia dalam memberi persepuluhan kepada Tuhan. Kedua, Untuk mencari tahu mengapa jemaat tidak memahami dengan benar tentang persepuluhan.

\section{Manfaat Penulisan}

Adapun manfaat penulisan karya ilmiah ini adalah: Pertama, Menjadi pedoman bagi pelayan-pelayan Tuhan pada umumnya secara khusus bagi pelayan-pelayan GSJA Victorious Worship Family Makassar dalam menanggulangi masalah persepuluhan. Kedua, Agar di dalam

\footnotetext{
${ }^{1}$ Robert Cowles, Gembala Sidang (Bandung: Kalam Hidup, 1993), 102.

${ }^{2}$ Ibid,102.

${ }^{3}$ Jeff Hammond, Perpuluhan 10\% (Jakarta: Immanuel, 2002), Viii.
} 
pelayanan penulis menggunakan upaya-upaya yang benar dalam memberikan pemahaman tentang persepuluhan. Ketiga, Sangat bermanfaat bagi penulis sebagai salah satu syarat dalam proses penyelesaian pendidikan Sarjana Pendidikan Agama Kristen di Sekolah Tinggi Filsafat Theologi Jaffray Makassar.

\section{Metodologi Penelitian}

Metode penelitian terbentuk dari dua kata yang terpisah yaitu metodologi dan penelitian. Metodologi berasal dari kata dasar metode yang artinya prosedur atau cara untuk mengetahui sesuatu dengan langkah-langkah yang sistematis. Penelitian adalah terjemahan dari kata Inggris "research". Research berasal dari kata "re" yang berarti "kembali" dan "to search" yang berarti "mencari". Dengan demikian penelitian secara etimologi berarti mencarai kembali." ${ }^{4}$ Secara terminologis penelitian adalah suatu prosedur pengkajian secara hati-hati dan kritis untuk mengetahui sesuatu dengan langkah-langkah yang sistematis.

Pengetahuan akan metodologi penelitian menolong peneliti untuk mengetahui urutan-urutan yang ditempuh dalam penelitian. Hal ini berhubungan erat dengan prosedur, alat ukur dan desain penelitian. Pengetahuan akan urutan-urutan tersebut dimaksudkan agar makalah yang dikaji dapat menghasilkan data yang akurat sehingga dapat dipertanggungjawabkan.

\section{Jenis Penelitian}

Jenis penelitian yang digunakan adalah penelitian kuantitatif. Penelitian kuantitatif adalah "penilitian yang berstandar pada kuantifikasi dalam pengumpulan dan analisis data untuk menguji hipotesis yang telah ditetapkan." ${ }^{5}$ Penalitian ini berusaha menjelaskan pengaruh pemberian persepuluhan atas perkembangan rohani jemaat GSJA Victorious Worship Family Makassar.

\section{Populasi Dan Sampel}

Adapun penelitian ini menggunakan populasi dan sample. "Populasi adalah di mana seorang peneliti akan memperoleh hasil penelitian yang dapat disamaratakan (digeneralisasikan)." Populasi penelitian ini ialah para anggota jemaat yang sudah berpenghasilan. Tetapi penulis menggunakan penelitian sample. "Sampel adalah proses pemilihan sejumlah individu atau dengan kata lain penarikan sebahagian dari populasi untuk mewakili seluruh populasi."” Jumlah anggota jemaat GSJA Victorious Worship Family Makassar secara keseluruhan adalah 180 jemaat dan 55 Kepala Keluarga (KK). Dalam penelitian akan mengambil sample yang terdiri dari 50 anggota jemaat yang sudah berpenghasilan.

\section{Pengumpulan Data}

Dalam penelitian lapangan, penulis menggunakan kuesioner sebagai teknik pengumpulan data. Peneliti memberikan kuesioner kepada anggota jemaat yang sudah berpenghasilan sebanyak 50 orang, di mana isinya yang menjelaskan tentang: Pertama, perkembangan rohani dari nomor satu sampai dengan nomor sembilan; Kedua, Keberhasilan jemaat dari nomor sepuluh sampai dengan nomor enam belas; Ketiga, sikap memberi dari nomor tujuh belas sampai dengan nomor dua puluh sembilan.

\footnotetext{
${ }^{4}$ Moh. Nazir, Metodologi Penelitian (Jakarta: Ghalia Indo, 1985), 13.

${ }^{5}$ Ibid, 14 . 2004), 57.

${ }^{6}$ Andres B. Subagyo, Pengantar Riset Kuantitatif dan Kualitatif(Bandung: Yayasan Kalam Hidup,

${ }^{7}$ Winarno Surakhmand, Dasar dan Teknik Research (Bandung: Tarsita, 1978), 84.
} 


\section{Teknik Analisis Data}

Teknik analisis data yang digunakan dalam penelitian ini ialah statistic dengan rumusan korelasi product moment untuk mencari sejauh mana sikap jemaat dalam hal persepuluhan berpengaruh atas perkembangan rohani jemaat dan sejauh mana sikap jemaat dalam hal persepuluhan berpengaruh atas keberhasilan usaha jemaat akan dianalisis dalam program SPSS 15 yaitu metode pengukuran teknik skala. Metode pengukuran teknik skala ini terdiri dari: Pertama, likert atau metode "summated ratinguttman. Menurut James A. Black bahwa; "metode pengukuran varial social dan variable psikologis biasanya menggunakan beberapa metode yang sudah dikenal luas, yang dirancang oleh peneliti. Dalam bagian ini James A. Black akan menjelaskan secara rinci beberapa metode sebagai berikut: Pertama, likert atau metode "summated rating", Kedua, thurstone atau pengukuran "equal appearing internd", dan Ketiga, pengukuran guttman. Beberapa metode tersebut merujuk pada sejumlah jenis teknik skala. Teknik skala (scaling) adalah proses penyusunan suatu standar pengukuran, ketika individu dibandingkan satu sama lain berdasarkan pangkat yang dimilikinya." ${ }^{8}$

\section{HASIL PENELITIAN}

Tabel 3

Hubungan Tingkat Pendidikan Dan Keberhasilan Usaha M-Estimators

\begin{tabular}{|l|c|c|c|c|c|}
\hline & $\begin{array}{l}\text { Tingkat } \\
\text { Pendidikan }\end{array}$ & $\begin{array}{c}\text { Huber's M- } \\
\text { Estimator(a) }\end{array}$ & $\begin{array}{c}\text { Tukey's } \\
\text { Biweight(b) }\end{array}$ & $\begin{array}{c}\text { Hampel's M- } \\
\text { Estimator(c) }\end{array}$ & $\begin{array}{c}\text { Andrews' } \\
\text { Wave(d) }\end{array}$ \\
\hline $\begin{array}{l}\text { Keberhasilan } \\
\text { Usaha }\end{array}$ & SMP & 17.96 & 17.74 & 17.82 & 17.74 \\
\hline & SMA & 18.28 & 18.08 & 18.17 & 18.08 \\
\hline & Diploma & 18.00 & 18.27 & 18.03 & 18.28 \\
\hline & Sarjana & 18.30 & 18.28 & 18.29 & 18.28 \\
\hline
\end{tabular}

Data di atas memberikan keterangan bahwa ada yang responden tidak capai dalam keberhasilan usaha jika dihubungkan dengan tingkat pendidikan. Hal itu bisa dilihat pada tingkat pendidikan SMP, di mana tingkat pendidikan SMP hanya memperoleh nilai 17,74. Dari 50 angket yang dijalankan ada 9 responden yang menjawab bahwa tatkala mereka memberi persepuluhannya kepada Tuhan, maka mereka kurang mengalami keberhasilan usaha, mungkin karena responden memberi persepuluhannya kepada Tuhan hanya supaya mendapatkan balasannya.atau mungkin karena mereka tidak bijksana dalam memberi.

\section{Tabel 4}

Hubungan Tingkat Pendidikan Dan Perkembangan Rohani

M-Estimators(e)

\begin{tabular}{|l|c|c|c|c|c|}
\hline & $\begin{array}{l}\text { Tingkat } \\
\text { Pendidikan }\end{array}$ & $\begin{array}{c}\text { Huber's M- } \\
\text { Estimator(a) }\end{array}$ & $\begin{array}{c}\text { Tukey's } \\
\text { Biweight(b) }\end{array}$ & $\begin{array}{c}\text { Hampel's M- } \\
\text { Estimator(c) }\end{array}$ & $\begin{array}{c}\text { Andrews' } \\
\text { Wave(d) }\end{array}$ \\
\hline $\begin{array}{l}\text { Perkembangan } \\
\text { Rohani }\end{array}$ & SMP & 21.66 & 21.13 & 21.17 & 21.13 \\
\hline & SMA & 21.44 & 20.55 & 21.71 & 20.50 \\
\hline & Diploma &. &. &. &. \\
\hline & Sarjana & 19.08 & 18.72 & 19.04 & 18.72 \\
\hline
\end{tabular}

${ }^{8}$ James A. Black \& Dean J. Champion, Metode Dan Masalah Penelitian Sosial (Bandung: PT. Refika Aditama, 1999), 162-163. 
Data di atas memberikan keterangan bahwa ada yang responden tidak capai dalam hal perkembangan rohani jika dihubungkan dengan tingkat pendidikan. Hal itu bisa dilihat pada tingkat pendidikan Sarjana, di mana tingkat pendidikan Sarjana hanya memperoleh nilai 19,08. Dari 50 angket yang dijalankan ada 3 responden yang menjawab bahwa tatkala mereka memberi persepuluhannya kepada Tuhan mereka kurang mengalami perkembangan rohani, mungkin karena responden memberi persepuluhannya kepada Tuhan hanya supaya dilihat orang lain bahwa tatkala semakin meningkat tingkat pendidikannya maka semakin meninkgat pula tingkat pemberiannya.

Table 5

Regresi Keberhasilan Usaha Coefficients(a)

\begin{tabular}{|c|c|c|c|c|c|c|}
\hline \multirow{2}{*}{\multicolumn{2}{|c|}{ Model }} & \multicolumn{2}{|c|}{$\begin{array}{l}\text { Unstandardized } \\
\text { Coefficients }\end{array}$} & \multirow{2}{*}{$\begin{array}{c}\text { Standardized } \\
\text { Coefficients } \\
\text { Beta }\end{array}$} & \multirow{2}{*}{$\frac{t}{B}$} & \multirow{2}{*}{$\begin{array}{c}\text { Sig. } \\
\\
\text { Std. Error }\end{array}$} \\
\hline & & B & Std. Error & & & \\
\hline 1 & $\begin{array}{l}\text { (Constant) } \\
\text { Perkembangan } \\
\text { Rohani } \\
\text { Sikap Memberi }\end{array}$ & $\begin{array}{l}27.331 \\
-.092 \\
-.294\end{array}$ & $\begin{array}{l}2.887 \\
.058 \\
.081\end{array}$ & $\begin{array}{r}-.248 \\
-.570\end{array}$ & $\begin{array}{r}9.466 \\
-1.584 \\
-3.642\end{array}$ & $\begin{array}{l}.000 \\
.120 \\
.001\end{array}$ \\
\hline
\end{tabular}

Tabel di atas menunjukkan nilai constant (y) adalah 9,466, nilai $b_{1} x_{1}$ adalah $(-1,584)$ dan $\mathrm{b}_{2} \mathrm{x}_{2}$ adalah $(-3,642)$. Persamaan regresi untuk hal ini adalah $\mathrm{Y}=\mathrm{a}+\mathrm{b}_{1} \mathrm{x}_{1}+\mathrm{b}_{2} \mathrm{y}_{2}$ di mana: $\mathrm{Y}=$ Keberhasilan usaha

$\mathrm{X}_{1}=$ Perkembangan rohani

$\mathrm{X}_{2}=$ Sikap memberi.

Maka $Y=9,466+(-1,584) x_{1}+(-3,642) x_{2}$ $=4,24$.

Jadi, Y adalah keberhasilan usaha, $\mathrm{X}_{1}$ adalah perkembangan rohani, nilai koefisien perkembangan rohaninya $-1,584$. Oleh karena nilainya mines berarti hubungan keberhasilan usaha dan perkembangan rohani berbanding terbalik. Artinya ketika rohani berkembang maka perkembangan usaha mengalami penurunan.

Seyogyanya memberi persepuluhan adalah suatu motivasi yang muncul dari hati kita, dan karena persepuluhan itu juga adalah suatu perintah Tuhan. Jadi, memberi persepuluhan bukan suatu investasi atau supaya mendapatkan balasan 


\section{KESIMPULAN}

Berdasarkan hasil penelitian dan pembahasan dalam penulisan skripsi ini, maka penulis menarik kesimpulan sebagai berikut:

Pertama, bahwa tingkat pendidikan jemaat GSJA Victorious Worship Family Makassar sangat berpengaruh terhadap perkembangan rohani jemaat, di mana apabila terjadi peningkatan pada tingkat pendidikan jemaat maka perkembangan rohaninya mengalami penurunan.

Kedua, bahwa tingkat pendidikan jemaat GSJA Victorious Worship Family Makassar sangat berpengaruh terhadap keberhasilan usaha jemaat, di mana apabila terjadi peningkatan pada tingkat pendidikan jemaat maka keberhasilan usaha jemaat mengalami peningkatan.

Ketiga, bahwa tingkat pendidikan jemaat GSJA Victorious Worship Family Makassar sangat berpengaruh terhadap sikap memberi persepuluhan kepada Tuhan, di mana apabila terjadi peningkatan pada tingkat pendidikan maka tingkat sikap memberi persepuluhan kepada Tuhan mengalami perkembangan.

\section{Saran-Saran}

Adapun saran-saran yang penulis ingin sampaikan sehubungan dengan "Pengaruh Pemberian Persepuluhan Atas Perkembangan Rohani Gereja Sidang Jemaat Allah Jemaat Victorious Worship Family Makassar", adalah sebagai berikut:

Pertama, setiap orang percaya, gembala atau pemimpin jemaat hendaknya menjadikan persepuluhan sebagai suatu gaya hidup secara khusus di GSJA Victorious Worship Family Makassar, melalui cara ini akan memberi pengaruh yang positif terhadap pertumbuhan gereja.

Kedua, sebagai anggota jemaat hendaknya mengingat tanggung jawab memberi persepuluhan kepada Allah melalui gereja, dengan cara demikian akan meningkatkan pertumbuhan kerohanian jemaat dan meningkatkan pertumbuhan ekonomi anggota jemaat.

Ketiga, sebagai gembala atau pemimpin jemaat hendaknya mengajarkan konsep sikap yang benar dalam memberi persepuluhan kepada Tuhan, dengan cara demikian persembahan umat-Nya akan menjadi persembahan yang berkenan di hadapan Tuhan.

Keempat, Muliakanlah TUHAN dengan hartamu dan dengan segala hasil pertama dari segala penghasilanmu, maka lumbung-lumbungmu akan diisi penuh sampai melimpahlimpah, dan bejana pemerahanmu akan meluap dengan anggurnya (Amsal 3:9-10).

\section{Ucapan Terima kasih}

Bpk.Pdt. John Ingatum S.Th dan Ibu Pdt. Yenni Ingatum selaku gembala sidang GSJA jemaat VWF Makassar, yang juga sebagai orang tua rohani bagi penulis yang selalu setia mendoakan dan memberi dukungan bagi penulis. Seluruh Staf Pastoral GSJA VWF Makassar yang telah mengizinkan dan memungkinkan penulis untuk melakukan penelitian, Bapak Yohanis yang telah membantu penulis dalam pengetikan skripsi ini. 


\section{KEPUSTAKAAN}

Alkitab

Alkitab. Jakarta: Lembaga Alkitab Indonesia, 1997.

Alkitab Penuntun Hidup Berkelimpahan. Malang: Gandum Mas, 1995.

Buku-Buku

Anette \& Jeff Hammond. Perpuluhan 10\%. Jakarta: Yayasan Pekabaran Injil "IMANUEL", 2002.

Cowles, Robert. Gembala Sidang. Bandung: Kalam Hidup, 1993.

Nazir. Moh. Metodologi Penelitian. Jakarta: Ghalia Indo, 1985.

Surakhman Wiranti. Dasar \& Teknik Research Pengantar Metodologi Ilmiah. Bandung: Tansito, 1978. 